\title{
O cenário da cultura e das práticas escolares na escola normal (1946-1971):
}

\section{Contribuições para a formação de professoras}

\author{
The scenario of culture and school practices in the normal school (1946-1971): Contributions to \\ teacher education
}

El escenario de la cultura y las prácticas escolares en la escuela normal (1946-1971): Aportes a la formación del profesorado

\section{Resumo}

Este artigo apresenta o recorte de uma pesquisa desenvolvida em um curso de Mestrado Acadêmico em Ensino de uma universidade do interior do Rio Grande do Sul, Brasil. Objetivou-se investigar que práticas escolares permearam a Escola Normal e a cultura dessa instituição educacional, no cenário sócio-histórico brasileiro, no período de 1946 a 1971. O recorte temporal marca a trajetória existencial da legislação brasileira dessa formação. Metodologicamente, trata-se de uma pesquisa qualitativa e bibliográfica, sendo os dados empíricos obtidos no Catálogo de Teses e Dissertações da CAPES, analisados com base na Análise de Conteúdo. Encontraram-se 13 estudos (dez dissertações e três teses), os quais emergiram as seguintes categorias: (a) origem da escola normal, (b) sua expansão, (c) e declínio. Resultados indicaram que no período de formação das normalistas, a escola tradicional imperou, suas práticas foram construídas em um universo repressor, impregnado de dogmas, entre contradições e dilemas políticos, ideológicos, de gênero e de classe, refletidos nas atuações profissionais das normalistas. Por fim, espera-se que pesquisas como esta, possam clarificar os aspectos históricos e as práticas formativas, expondo às intencionalidades, que estabeleceu, distinguiu e, pelo que vimos, desvalorizaram essas instituições.

Palavras-chave: Escola normal; Formação de professores; Práticas escolares; História da educação.

\begin{abstract}
This article presents the excerpt of a research developed in an Academic Masters in Teaching course at a university in the interior of Rio Grande do Sul, Brazil. It aimed to investigate which school practices permeated the Escola Normal and the culture of this educational institution, in the Brazilian socio-historical scenario, from 1946 to 1971 . The time frame marks the existential trajectory of the Brazilian legislation for this training. Methodologically, this is a qualitative and bibliographic research, with empirical data obtained from the CAPES Theses and Dissertations Catalog, analyzed based on Content Analysis. Thirteen studies were found (ten dissertations and three theses), which emerged in the following categories: (a) origin of the normal school, (b) its expansion, (c) and decline. Results indicated that in the period of formation of the normalists, the traditional school reigned, their practices were built in a repressive universe, impregnated with dogmas, between contradictions and political, ideological, gender and class dilemmas, reflected in the professional performances of the normalists. Finally, it is hoped that research like this can clarify the historical aspects and training practices, exposing the intentions that established, distinguished and, from what we have seen, devalued these institutions.
\end{abstract}

Keywords: Normal school; Teacher training; School practices; History of education.

\section{Resumen}

Este artículo presenta el extracto de una investigación desarrollada en un curso de Maestría Académica en Docencia en una universidad del interior de Rio Grande do Sul, Brasil. Su objetivo fue investigar qué prácticas escolares 
impregnaron la Escola Normal y la cultura de esta institución educativa, en el escenario socio-histórico brasileño, de 1946 a 1971. El marco temporal marca la trayectoria existencial de la legislación brasileña de esta formación. Metodológicamente, se trata de una investigación cualitativa y bibliográfica, con datos empíricos obtenidos del Catálogo de Tesis y Disertaciones CAPES, analizados en base al Análisis de Contenido. Se encontraron trece estudios (diez disertaciones y tres tesis), que surgieron en las siguientes categorías: (a) origen de la escuela normal, (b) su expansión, (c) y declive. Los resultados indicaron que en el período de formación de los normalistas, imperaba la escuela tradicional, sus prácticas se construyeron en un universo represivo, impregnado de dogmas, entre contradicciones y dilemas políticos, ideológicos, de género y de clase, reflejados en las actuaciones profesionales de los normalistas. Finalmente, se espera que investigaciones como esta puedan esclarecer los aspectos históricos y las prácticas formativas, exponiendo las intenciones que establecieron, distinguieron y, por lo visto, devaluaron estas instituciones.

Palabras clave: Escuela normal; Formación del profesorado; Prácticas escolares; Historia de la educación.

\section{Introdução}

Uma instituição escolar de ensino possui regras advindas do meio externo (do social), mas tem também uma relativa autonomia, cujos paradigmas do período histórico em que existe, comandam suas ações. Essas ações constituem as práticas escolares de sua cultura, que são únicas em cada coletividade e, fomentam a história e memória local de cada comunidade, que às têm como símbolo patrimonial histórico de sua identidade social. (Ortiz, 2014; Lemiechek, 2014; Louzada, 2018; Marinho, 2008; Santiago, 2015; Vasconcelos, 2014).

$\mathrm{Na}$ intenção de compactuar com Nunes (2006), quando diz que vê a História da Educação como possibilidade de desenvolvimento de cidadania, uma demanda que provém da sociedade e exige do sujeito pesquisador uma escrita que venha despertar inquietações e dúvidas e que possam promover o senso crítico em busca de quebras de paradigmas, o texto aqui descrito emerge na tentativa de elucidar e responder a seguinte questão problema: Qual era a cultura escolar da Escola Normal no Brasil, suas práticas e representações produzidas na/para formação de professoras no período de 1946 a 1971 ?

Procura-se no passado expor e estabeler um possível diálogo entre tempos históricos e suas configurações sociais, as raízes que conduzem o trabalho docente na educação básica brasileira através da investigação sobre a cultura da Escola Normal, as práticas escolares na formação de professoras e suas representações, na História da Educação, em busca de possíveis reflexões sobre a cultura das escolas brasileiras.

Para tanto, objetivou-se neste artigo, investigar que práticas escolares permearam a Escola Normal e a cultura dessa instituição educacional, no cenário sócio-histórico brasileiro. O recorte temporal de 1946 a 1971, marca a trajetória especificamente da existência na legislação brasileira dessa formação - ascensão e decadência do Curso Normal, que formava as Normalistas, demarcado pela Lei Orgânica do Ensino Normal - n. 8.530/46 (Brasil, 1946) e as Leis de Diretrizes e Bases da Educação Nacional - n. 4.024/61 (Brasil, 1961) e n. 5.692/71 (Brasil, 1971).

Os dados empíricos foram obtidos por meio de estudos encontrados no Catálogo de Teses e Dissertações da Coordenação de Aperfeiçoamento de Pessoal de Nível Superior (CAPES), conforme critérios apresentados a seguir, e analisados com base na Análise de Conteúdo (Bardin, 2011).

\section{Metodologia}

Metodologicamente classifica-se quanto a natureza como qualitativa, descrita por Gil (2017) como uma sequência de procedimentos que incluem a redução dos dados, sua classificação, interpretação e redação do relatório. Neste tipo de investigação o desenvolvimento de conceitos é gerado a partir "[...] do entendimento indutivo e interpretativo que se atribui aos dados descobertos, associados ao problema de pesquisa” (Soares \& Fonseca, 2019, p. 169). Já no concernente aos procedimentos técnicos trata-se de uma pesquisa bibliográfica, visto que analisa documentos já elaborados, neste caso, dissertações e teses (Gil, 2017). 
Para obtenção dos dados empíricos, pesquisou-se no Catálogo de Teses e Dissertações da CAPES, no mês de outubro de 2019, o seguinte descritor: "Escola Normal” (singular) OR “Escolas Normais" (plural). A aplicação das aspas e do operador OR restringiu os resultados da busca aos termos exatos. O corpus de análise foi refinado até a obtenção quantitativa inferior a 150 resultados, seguindo os critérios: (1) publicação dos últimos dez anos [2008-2018], sendo 2019 desconsiderado por estar em andamento na época da busca (2) e Área de Concentração em Educação, escolha intencional pela especificidade da pesquisa.

Na sequência, a partir da leitura atenta dos títulos, resumos e palavras-chave, selecionou-se aquelas que tinham recorte temporal entre ou aproximado de 1946 a 1971 e que relatassem a história da educação da Escola Normal, da cultura e das práticas escolares dessa instituição formadora de professores no Brasil.

Por fim, a análise técnico-metodológica pautou-se na Análise de Conteúdo descrita por Laurence Bardin (2011), que consistiu em: pré-análise; exploração do material; e tratamento dos resultados, inferência e interpretação. Os resultados são apresentados por meio de categorias e síntetizados em ilustrações, que expõem as concepções advindas do referencial teórico. As categorias elencadas foram: (1) a origem da Escola Normal no ensino brasileiro, (2) a expansão do ensino normal no Brasil, (3) e o declínio da Escola Normal formadora de professoras primárias.

\section{Resultados e Discussão}

A partir da busca do descritor "Escola Normal" OR "Escolas Normais" no Catálogo de Teses e Dissertações da CAPES obtiveram-se 744 resultados (223 teses e 521 dissertações). O refinamento temporal (2008-2018) resultou em 441 estudos (144 teses e 297 dissertações) e por Área de Concentrou (Educação) finalizou-se a busca com 127 (46 teses e 81 dissertações).

Destas 127 pesquisas, a leitura dos títulos, resumos e palavras-chave identificou que 24 enquadravam-se nos critérios de seleção. Contudo, o corpus de análise foi restrito a 13 (dez dissertações e três teses), descritas no Quadro 1. As demais não possuíam divulgação autorizada ou não tinham a Escola Normal como foco de estudo.

Quadro 1: Estudos escolhidos para compor o corpus de análise.

\begin{tabular}{|c|c|c|c|}
\hline & Autoria & Ano & Título \\
\hline \multirow{3}{*}{ 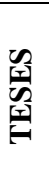 } & Louzada, Maria Cristina do Santos. & 2018 & $\begin{array}{l}\text { Memórias e trajetórias de egressas das Escolas Normais Assis Brasil e São } \\
\text { José em Pelotas/RS, no período do governo de Leonel Brizola (1959-1963). }\end{array}$ \\
\hline & Martins, Ana Maria Gomes de Sousa. & 2016 & $\begin{array}{l}\text { A formação de professores primários no Piauí (1947-1961): entre as } \\
\text { apropriações e mudanças decorrentes da lei orgânica do ensino normal. }\end{array}$ \\
\hline & Moraes, Andreia Demetrio Jorge. & 2014 & História e memória da formação docente em Ituiutaba - MG. \\
\hline \multirow{10}{*}{ 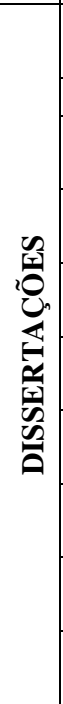 } & Andrade, Fabiana Aparecida de. & 2016 & $\begin{array}{l}\text { Colégio das freiras: educação feminina no Curso Normal no sul de Goiás } \\
(1939 / 1968) \text {. }\end{array}$ \\
\hline & Bezerra, Arthur Damico. & 2015 & A Escola Normal de Ponta Porã, sul de Mato Grosso (1959- 1974). \\
\hline & Carvalho, Luciana Belíssimo de. & 2014 & $\begin{array}{l}\text { Implantação e consolidação da escola normal no sul de Mato Grosso: Escola } \\
\text { Normal Jango de Castro, Aquidauana (1949-1975). }\end{array}$ \\
\hline & Inácio, Clarissa Betanho. & 2017 & $\begin{array}{l}\text { Estado militar e educação e a formação de professores: as iniciativas da } \\
\text { Escola Normal de Uberlândia }(1970 \text { - } 1980) \text {. }\end{array}$ \\
\hline & Lemiechek, Lucimara. & 2014 & $\begin{array}{l}\text { Aspectos históricos da formação de professores normalistas no município de } \\
\text { Laranjeiras do sul - PR (1946-1980). }\end{array}$ \\
\hline & Marinho, Joseanne Zingleara. & 2008 & $\begin{array}{l}\text { Entre Letras e Bordados: o tecer das tramas na história das normalistas em } \\
\text { Teresina (1930-1949). }\end{array}$ \\
\hline & Moura, Suely Barbosa de. & 2014 & $\begin{array}{l}\text { O Colégio São José e a formação das professoras normalistas em Caxias - } \\
\text { Maranhão: formando para a igreja, para a pátria e o lar }(1949-1972) \text {. }\end{array}$ \\
\hline & Ortiz, Fernanda Ros. & 2014 & $\begin{array}{l}\text { A escola normal de moças das elites: um estudo das práticas escolares, } \\
\text { culturais e sociais do colégio nossa senhora auxiliadora }(1946-1961) \text {. }\end{array}$ \\
\hline & Santiago, Alda Margarete Silva Farias. & 2015 & $\begin{array}{l}\text { Vozes e saudades: as narrativas das ex-alunas sobre a Escola Normal } \\
\text { Regional Nossa Senhora da Assunção - Guimarães/MA (1957-1961). }\end{array}$ \\
\hline & Simões, Caroline Hardoim. & 2014 & $\begin{array}{l}\text { A formação de professores na Escola Normal Joaquim Murtinho no sul de } \\
\text { Mato Grosso no período de } 1930 \text { a } 1973 \text {. }\end{array}$ \\
\hline
\end{tabular}

Fonte: Autores(2021). 


\section{Categoria um: A origem da Escola Normal no ensino brasileiro, uma instância tradicional de socialização}

No Brasil, desde a organização social colonial, do século XVIII, havia uma sociedade latifundiária, escravocrata e aristocrática, que necessitava apenas de pessoas incultas e submissas - os servidores, a educação era voltada a reforçar o sistema sóciopolítico daquela era, endossado pela poder da Igreja. Aos poucos foi sendo tirado o poder da Igreja e colocado nas mãos do Estado, uma educação voltada, a partir daí, para cumprir com os interesses do Estado. No início do século XIX a classe emergente, a pequena burguesia, considerando baixo o nível das escolas oficiais brasileiras, incentivava as escolas particulares, voltadas para a elite governante, espaço onde seus filhos estavam matriculados com o objetivo de que ao concluírem o nível secundário e/ou superior fossem os futuros administradores do país (Araújo, Freitas \& Lopes, 2017).

Na década de 1920, começa o declínio das oligarquias, do modelo agrário-comercial-exportador e o impulso à industrialização com o modelo nacional-desenvolvimentista. Em 1930, é criado o Ministério da Educação e Saúde, pasta ocupada por Francisco Campos, que organiza a reforma do ensino secundário definindo o currículo seriado, a frequência obrigatória, dois ciclos, um fundamental de cinco anos e o outro complementar de dois anos, e a exigência de habilitação neles para ingresso no curso superior. De 1931 a 1937, congressos, seminários e conferências foram realizados, com embates entre escolanovistas e intelectuais católicos, que foram em partes contemplados pelas políticas públicas visando um arrefecimento dos ânimos. O ano de 1937 foi marcado pela instauração do Estado Novo, regime ditatorial, de Vargas (Araújo, Freitas \& Lopes, 2017; Moraes, 2014; Nosella \& Buffa, 2002; Ribeiro, 1993; Saviani, 2009, 2013; Tanuri, 2000).

No período de 1940, a oligarquia cafeeira e a burguesia industrial vinham realizando uma queda de braço, que resultou no fim da chamada República Velha e a tomada do poder por Getúlio Vargas. A educação começa a mudar, em resposta às novas necessidades da industrialização do país, que precisava de mão de obra melhor qualificada, para as funções que se abriam no mercado de trabalho, havendo uma tentativa de se traçar uma política educacional de âmbito nacional. Em 1942, com a Reforma Capanema, a ideologia educacional foi voltada para o patriotismo e o nacionalismo, impondo disciplina e ordem através dos cursos de moral e civismo e de educação militar para os alunos do sexo masculino nas escolas secundárias. O ensino secundário passou a ser ministrado em dois ciclos de quatro e três anos. Os primeiros quatro anos correspondiam ao curso ginasial e os três últimos ao curso colegial, que apresentava duas opções: o clássico e o científico. Várias legislações resultaram na organicidade do sistema educacional brasileiro. Dentre elas, a Lei Orgânica do Ensino Normal (LOEN), DecretoLei n. 8.530, de 1946, que preconizou uma certa uniformidade na formação para o magistério, esse ensino que foi abarcado pelas escolas de cunho religioso, principalmente escolas católicas, mais conhecidas como Escola das Freiras (Marinho, 2008; Andrade, 2016). O ensino constituía-se em valores cívicos, sociais, dogmáticos e religiosos (Araújo, Freitas \& Lopes, 2017). Essa legislação dá, propriamente a origem a Escola Normal, padronizando-a no sistema de ensino brasileiro.

A partir das concepções dos estudos Andrade (2016), Araújo, Freitas e Lopes (2017), Bezerra (2015), Lemiechek (2014), Moura (2014), Marinho (2008), Ortiz (2014) e Simões (2014) construiu-se a Figura 1, que mostra os preceitos da Escola Normal de 1946. 
Figura 1: Os preceitos da Escola Normal de 1946.

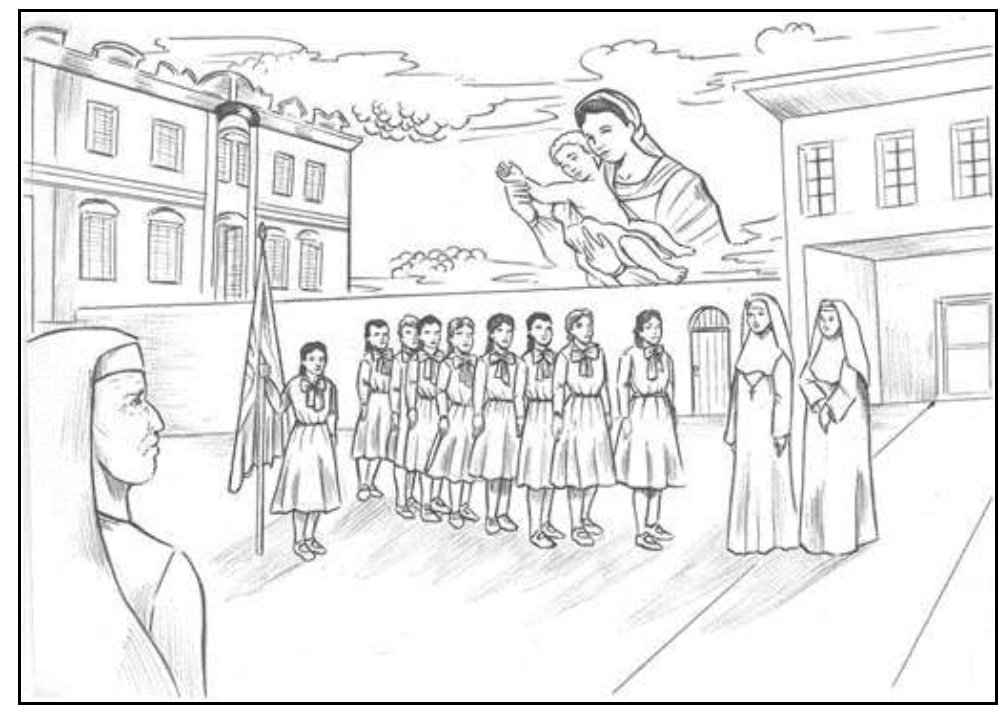

Fonte: Autor (2020).

Percebe-se, na imagem, alunas normalistas, em uma Escola Normal, uma escola particular, cristã, católica, em uma instituição com instalações amplas, edificação imponente, reservada da curiosidade da vida "lá fora"; instituição, na qual meninas-moças iniciavam seus estudos na formação de seus conhecimentos para atuar na sociedade como boas esposas, preparando-se para "o casamento" e para o ofício de professora. Fechadas, entre muros, em uma educação católica, formadora de elites intelectuais, na qual, a partir de uma educação conservadora a Escola Normal cumpria com o papel da formação da mulher da época (organizar, cuidar, educar) (Marinho, 2008).

Em vários municípios foram construídas escolas como expoentes do ensino, muitas em locais onde não tinha qualquer estrutura de moradia, transporte ou mesmo higiene - carentes e em desenvolvimento. Azevedo e Stamatto (2012, p. 32) colocam que: “[...] os prédios escolares fizeram parte da produção da leitura da modernidade e do progresso feita pelas elites locais e se transformaram em um dos alvos prediletos para a difusão do ideário republicano". Ortiz (2014) revela que a educação ministrada nas escolas normais era pautada em disciplina, bom comportamento, obediência, preceitos morais e valores “[...] da instituição religiosa”, como se demonstra na Figura 1.

Escolano e Frago (2001, p. 47) dizem que "[...] a escola, em suas diferentes concretizações, é um produto de cada tempo, e suas formas construtivas são, além dos suportes da memória coletiva cultural, a expressão simbólica dos valores dominantes nas diferentes épocas". Observa-se, na ilustração, que o teor cristão religioso dogmático impera, acima das cabeças das estudantes, Nossa Senhora contempla suas "protegidas”, que em fila, organizadas, obedientes muito jovens, colocam-se aos cuidados das Irmãs, religiosas, zeladoras de seus preceitos e valores cívicos, morais e sociais, "donas de seus pensamentos", que "passavam" os conhecimentos à essas futuras professoras da nação. Uma jovem estudante, empunha a bandeira, que pode ser da escola ou da nação, representavam a força que as moviam em seus estudos, na intenção de serem "boas representantes da sociedade", "adequadas aos seus papéis" naquele momento histórico.

\section{Categoria dois: A expansão do Ensino Normal no Brasil}

Braga e Mazzeu (2017, p. 26) colocam as taxas de analfabetismo no Brasil, no período de 1940 a 1970: 1940 (56,1\%); $1950(50,5 \%) ; 1960(39,7 \%)$ e 1970 (33,7\%), em declínio, considerando a expansão do ensino primário e a formação de

\footnotetext{
${ }^{1}$ A ilustração foi desenhada pelo artista Alex Sandro Machado da Rosa, Bagé/RS.
} 
profissionais para esse ensino, na Escola Normal. Simões (2014) expõe que a gênese da Escola Normal, primeiro se deu de forma descontínua, só se fortalecendo nos anos de 1950 e 1960, como único espaço formador de professores qualificados para atuar no ensino primário, em caráter terminal e profissionalizante, em uma época em que o acesso ao ensino superior das normalistas era limitado a alguns cursos da faculdade de Filosofia. Tanuri (2000) evidencia que a grande maioria dos estados tomou a Lei Orgânica do Ensino Normal (LOEN), como "[...] modelo para reorganização de suas escolas normais, o que contribuiu para que se consolidasse em todo o país um padrão semelhante de formação, ainda que diversificado em dois níveis de escolas" (Tanuri, 2000, p. 77). O autor coloca, que esta lei, a LOEN, no entanto, consagrou um padrão que já vinha sendo adotado nas escolas normais do país. Aumentou o acesso ao ensino, mas não houve a preocupação com a qualidade da educação desenvolvida.

Andreotti (2006, p. 103), esclarece que "[...] de 1945 até 1961, período identificado como a segunda fase de industrialização e de ajuste do país ao desenvolvimento econômico mundial, assiste-se a uma ampla discussão sobre a necessidade de se criar uma legislação nacional com diretrizes para todos os graus ou áreas de ensino", discussão que depois de 13 anos, converteu-se na primeira Lei de Diretrizes e Bases da Educação, promulgada em 1961, Lei n. ${ }^{\circ}$ 4.024, que passou a dar autonomia aos Estados da Federação quanto às disciplinas ministradas no ensino secundário (médio). Essa Lei equiparou os cursos técnicos e o Curso Normal ao então ensino médio, se cumprisse com as exigências da legislação. Em seu artigo 34, prevê: "O ensino médio será ministrado em dois ciclos, o ginasial e o colegial, e abrangerá, entre outros, os cursos secundários, técnicos e de formação de professôres para o ensino primário e pré-primário" (Brasil, 1961). Nessa época os processos de urbanização, imigração e desenvolvimento nacional proporcionaram alguns parcos avanços na educação.

Louzada (2018), evidencia no Rio Grande do Sul, as adversidades educacionais advindas da incompetência dos governos anteriores, “[...] além da falta de vagas nas escolas primárias, do alto índice de analfabetismo e da intensa evasão escolar ainda na infância, destacava-se a questão da existência de poucos professores contratados para assumir a docência estadual." (Louzada, 2018, p. 119) Foram criadas 23 mil vagas de professores até o ano de 1962. Essas professoras iam atuar como contratadas por período letivo, a cada ano, renovava-se o contrato, em escolas construídas no Estado no Programa de Expansão Descentralizada do Ensino Primário. Prédios que ficaram conhecidos como "Brizoletas"”2. Na função de professoras contratadas tinham remuneração menor que as professoras nomeadas e não tinham direitos como licença-prêmio, ficavam por períodos longos para receber seus salários, como coloca uma das entrevistadas de Louzada (2018, p. 122) em sua pesquisa: “[...] não sei as outras, mas eu fiquei um ano sem receber". Outra de suas entrevistadas, relembra que Brizola foi o único governador que, mesmo deixando de pagar nove meses de salário, quando pagou, pagou também o mês de dezembro (Louzada, 2018). Fica claro que, apesar das adversidades mostravam gratidão ao governante por poder fazer parte do mundo do trabalho em uma época em que, para a mulher, isso era escasso. No estudo de Louzada (2018, p. 200), o lema, de uma turma de formandas, em 1960, descreve o pensamento dessas trabalhadoras na época: "Tudo para a criança e a criança para Deus".

Com base nos estudos de Araújo, Freitas e Lopes (2017), Inácio (2017), Louzada (2018), Moura (2014) e Ortiz (2014), elaborou-se a Figura 2, que mostra a atuação das normalistas, na década de 1960, no Rio Grande do Sul.

\footnotetext{
${ }^{2}$ As escolas tinham características próprias. Eram construídas em madeira e, no geral, tinham uma ou duas salas de aula e se popularizaram como as escolinhas do Brizola, ou as Brizoletas. [...] Os prédios escolares eram construídos às margens das estradas ou voltados para a rua, em vales e picadas, eram edifícios simples e modestos (Madeira, 2010 p. 68 apud. Louzada, 2018, p. 120). Nessas escolas, as normalistas recém contratadas assumiam turmas multisseriadas, da $1^{\text {a a }} 5^{\text {a }}$ série.
} 
Figura 2: atuação das normalistas, na década de 1960, no Rio Grande do Sul.

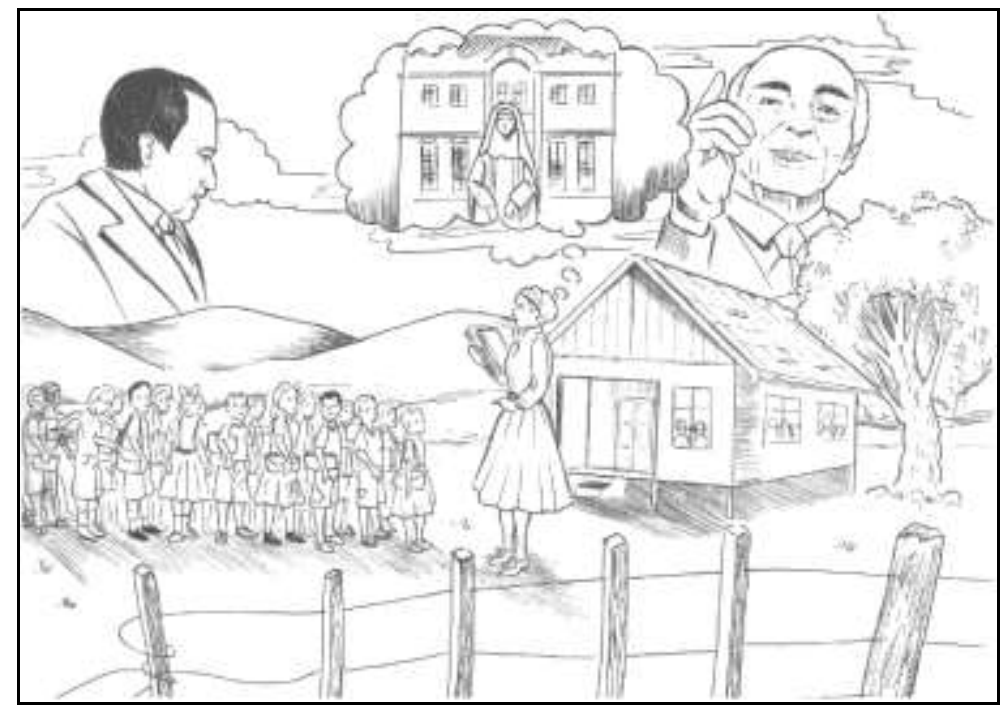

Fonte: Autor (2020). ${ }^{3}$.

A ilustração mostra o que se concebe ter sido a atuação das normalistas, na década de 1960, no Rio Grande do Sul. As Escolas Normais estavam em diversas cidades do Estado, formando as Normalistas. O Estado contratava, com a expansão do ensino primário, através das Delegacias Educacionais de Ensinos, essas jovens professoras e as encaminhava às escolas recém construídas no interior do RS, muitas vezes deixando seus familiares, essas profissionais adentravam o mundo do trabalho docente, na ânsia das remoções, esperando a possibilidades de retornarem aos seus municípios de origem e lá continuarem seu trabalho.

Na Figura 2, a normalista, recém formada, assume uma turma em uma escolinha, no interior, possivelmente uma "Brizoleta", os alunos, pequeninos, que buscavam a instrução de suas primeiras letras, vinham de toda parte das comunidades, a personagem lembra o espaço que a formou, a imponente escola particular, cristã, católica; e, a professora, a Irmã, que carinhosamente (ou não), ainda vem em sua mente como modelo de postura e ação profissional.

As práticas escolares dessa professora foram inspiradas nesses personagens. Louzada (2018, p. 127) destaca que “[...] para Frago (2011), no centro da ligação entre a memória e o patrimônio está a instituição educacional, foco de transmissão do saber e do conhecimento de um grupo social, onde é construída, através do tempo e dos espaços de interação, a história dos sujeitos que fazem parte daquele educandário". Assim sentia-se a normalista em sua memória, o respeito e a consideração pela instituição que lhe deu o sentido de identidade e de pertencimento.

Acima, à esquerda, a imagens do Presidente Getúlio Dornelles Vargas, que até 1954 comandou o sistema educacional brasileiro buscando unidade nacional e civismo patriótico. "O Pai dos Pobres", o presidente que uniu os trabalhadores do país. Acima, à direita, a imagem do Governador Leonel de Moura Brizola, eleito Governador do Estado em 03 de outubro de 1958, assumindo o Palácio Piratini, em 31 de janeiro de 1959, a cena remete possivelmente à decada de 1960 a 1964.

O período de Ditadura, a partir de 1964, compactuou e incentivou o ensino dado nas Escolas Normais, pois os princípios rígidos formativos estavam adequados ao momento, Inácio (2017, p. 87) afirma que a "[...] cidadania aprendida e praticada pelos brasileiros" era "centralizada no Estado e por ele vigiada". Apesar de terem sido criadas várias escolas técnicas no país até 1971, o Estado dispunha do financiamento de bolsas de estudo que eram distribuídas nas localidades onde funcionavam essas escolas particulares. As práticas escolares desenvolvidas pelas normalistas em suas escolas, continuaram,

${ }^{3}$ A ilustração foi desenhada pelo artista Alex Sandro Machado da Rosa, Bagé/RS. 
por esse período histórico, 1946 a 1971, inspiradas no ensino tradicional.

\section{Categoria três: $\mathbf{O}$ declínio da escola normal formadora de professoras primárias}

Com a publicação da Lei de Diretrizes e Bases da Educação Nacional, Lei nº 5.692, de 11 de agosto de 1971, as Escolas Normais e seus respectivos Cursos de Formação de Professores Primários foram substituídos pelo Curso de Magistério. O aluno que se formava neste curso recebia o Diploma de Professor do Ensino de Primeio Grau, que lhe conferia o título de "Professor do Ensino de Primeiro Grau, de $1^{\mathrm{a}}$ a $4^{\mathrm{a}}$ série", por ter concluído o seu ensino de segundo grau com a "Habilitação Profissional Plena para o Magistério". Um incentivo para o(a) trabalhador(a), que ao terminar o segundo grau já poderia rumar para o trabalho e despedir-se de maiores formações, visto que as Universidades não dispunham de vagas suficientes.

Ao longo do tempo estudado ocorreu a substituição de um ensino pautado em conteúdos culturais-cognitivos, para o modelo pedagógico-didático, como cita Saviani (2013), com prevalência deste primeiro sobre o segundo. Neste sentido, inspirado nas concepções de Andrade (2016), Araújo, Freitas e Lopes (2017), Moura (2014), Nóvoa (1995), Ortiz (2014), Santiago (2015) e Saviani $(2009,2013)$, criou-se a Figura 3, charge ilustrativa sobre o período de formação do ofício de professor no Brasil, nas Escolas Normais - formação de normalistas.

Figura 3: período de formação do ofício de professor no Brasil, nas Escolas Normais - formação de normalistas.

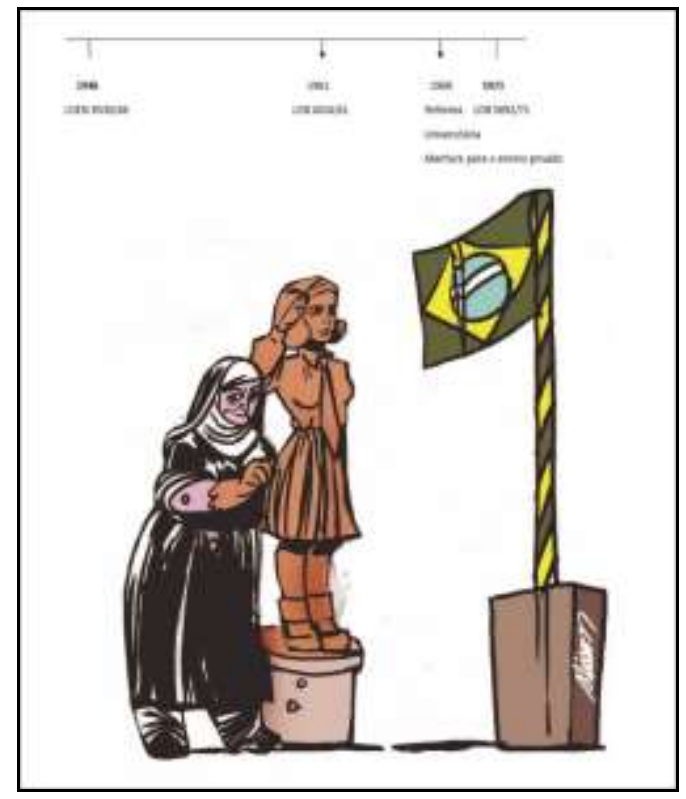

Fonte: Autora $(2020)^{4}$.

Percebe-se, na parte superior da charge, uma linha do tempo em que mostra a existência da Escola Normal, formadora das normalistas, período de ascensão e declínio dessa formação de professoras primárias no ensino secundário, em caráter terminal e profissionalizante. Na Linha do tempo está demarcado: 1946, LOEN n. 8.530/46 - primeira demarcação na Linha do tempo, acima; 1961, LDB n. 4.024/61 - segunda demarcação na Linha do tempo, acima; 1968, reforma universitária, abertura para o ensino privado; e 1971, LDB n. 5692/71. Antes de 1946, formavam-se Alunas-Mestras, ocasião em que se buscava uma prática escolar para formar "a elite intelectual"; a partir da LOEN, até a 1ªDB de 1961 buscava-se formar "o pretenso cidadão"; depois de 1971, formavam-se Professor do Ensino de Primeiro Grau, período em que, com uma estrutura

${ }^{4}$ A ilustração foi desenhada pelo artista Alisson Affonso, Rio Grande/RS. 
simplificada, a legislação transformou o Ensino Normal em uma formação estritamente técnica, visando por fim, formar "o trabalhador" (Andrade, 2016; Araújo, Freitas \& Lopes, 2017; Moura, 2014; Nóvoa, 1995; Ortiz, 2014; Santiago, 2015; Saviani, 2013).

A Figura 03, tem como proposta expor de forma crítica o período de formação das Normalistas no Brasil, na imagem uma representante do clã religioso esculpe a Normalista, que ao mesmo tempo se põe em continência, saindo das mãos do sistema religioso e se pondo à disposição do Estado, como o descrito na Canção do Exército Brasileiro, um soldado da nação em defesa de seus princípios progressistas, liberais e reformadores: "Nós somos da Pátria a guarda/Fiéis soldados [...] Em nosso valor se encerra/Toda a esperança/Que um povo alcança [...]”. Assim o poder público, apesar de propor inovações legislativas, via na educação o meio para a construção do consenso necessário ao formato do Estado e, os professores foram recrutados “[...] como tentáculos do poder político, na medida em que estivessem identificados com seus interesses" (Simões, 2014).

Desde a primeira Escola Normal (na França, em 1794), sendo a primeira brasileira, criada em Niterói, no Rio de Janeiro, no ano de 1835, essa escola tinha por objetivo formar professores para atuarem no magistério de ensino primário, nas escolas da nação - formar as Normalistas, para que estas consolidassem a unidade nacional, "formando para a igreja, para a Pátria e o lar" (Moura, 2014). Nóvoa (1995, p. 16), destaca que: “Ao longo do Século XIX consolida-se uma imagem de professor, que cruza as referências ao magistério docente, ao apostolado e ao sacerdócio, com a humildade e a obediência aos funcionários públicos". Só no mundo moderno pode-se conhecer uma estrutura pública de formação docente.

\section{Considerações Finais}

Este estudo teve como pretensão investigar quais foram as práticas escolares da Escola Normal diante do contexto sócio-histórico de 1947 a 1971 e a cultura dessa instituição educacional. Das 13 teses e dissertações analisadas, podemos inferir que o ensino variou de acordo com as práticas culturais e figurações socioeconômicas de cada época. Foi a institucionalização do ensino que criou o ofício de professor e as escolas normais. A legislação nacional imprimiu organicidade a esse ensino, a partir de 1946, com a Lei Orgânica do Ensino Normal (LOEN). Entre as décadas de 1940 e 1970 as práticas escolares dessa instituição, que versava formar professoras primárias, no secundário, em caráter terminal e profissionalizante, foram forjadas em um universo repressor, impregnado de dogmas, com um manual de ensino pautado no pensamento religioso, da escola cristã, principalmente católica, cujas ideias pedagógicas, didáticas e metodológicas foram permeadas por ritos e símbolos sagrados.

O ensino, inicialmente, era ofertado para uma classe social: a elite. Aos poucos, os bancos escolares dessa instituição foram sendo ocupados pela pequena burguesia. Quando o povo (das classes sociais mais baixas da sociedade brasileira) começou a invadir esse espaço e o Estado a abrir Escolas Normais Públicas, não houve interesse das políticas governamentais brasileiras em investimento necessário nesse setor e as instituições religiosas abriram mão desse segmento, imprimindo o declínio da Escola Normal, essa instância tradicional de socialização, que formava as Normalistas - professoras primárias brasileiras.

A cultura e as práticas escolares da Escola Normal mudaram muito pouco nesse período estudado, permaneceu um ensino enciclopédico, tendo as concepções tradicionais de ensino como arcabouço teórico - a escola tradicional imperou por todo esse tempo. As mudanças, nessa ordem social histórica, na cultura e nas práticas escolares, neste ensino secundário, de 1940 a 1970, deram-se no Ensino Normal, pelas apropriações das incorporações das prescrições curriculares das disciplinas, pela nova organização do curso normal, pelos mecanismos avaliativos do conhecimento escolar, pelo fim da segregação de gênero, em relação aos estabelecimentos de ensino, e, pelos instrumentos de fiscalização, supervisão e controle dessa instrução, 
que inseriram-se a partir de 1968/70.

$\mathrm{Na}$ Escola Normal se encontra as produções sociais sobre a formação docente, recuperar a trajetória dessas instituições e seus atores, demonstrar a participação no desenvolvimento da comunidade em que está inserida, constitui-se em uma utilidade social, que irá contribuir para a escrita da formação de professoras na História da Educação, pois permite um recontar das singularidades históricas. Cujo olhar para esse patrimônio demanda o entendimento proposto por Ipólito e Almeida (2020), de que o desenvolvimento da sociedade é resultado de um processo, no qual as mudanças acontecem de forma lenta, gradual e as concepções de mundo coexistem, convivem, dialogam e sempre deixam seus legados.

Considera-se que essa pesquisa foi de valia para a aproximação dos pesquisadores com o tema estudado e para evidenciar os fatos do cenário sócio-político-econômico, gerador de políticas públicas para o ensino brasileiro, que imprimiram as ações educativas das práticas escolares na Escola Normal (1946-1971), influenciaram e ainda hoje influenciam por reflexo social, interferindo na construção da identidade docente no Brasil, que precisa levar em conta esses aspectos do cenário que delineou as práticas escolares muitas vezes, sedimentadoras de uma cultura escolar identificada, hoje, como injusta, ideológica, dogmática, segregacionista e excludente, advinda do reflexo da própria cultura escolar, enquanto estudante.

Como pesquisadores e professores identificamos que no mundo do trabalho docente, há exigênca de uma dinâmica social de aprendizado constante, mas também, a necessidade de uma análise histórica, da compreensão dessa teia de ações, que o profissional da educação deve ter, sobre sua formação. Nesse sentido compreendemos a importância deste estudo. Exercitar a reflexão sobre as raízes que imprimiram a formação das Normalistas permite nossa própria percepção do processo educativo construído diariamente na escola em que atuamos, reflexo do processo formativo.

Diante do exposto, esperamos, com este estudo, contribuir para a escrita da formação de professoras na História da Educação, pois essas práticas da Escola Normal, compreendidas em sua complexidade sócio histórica, possibilitarão a consciência histórica, que é o maior benefício da História - a consciência crítica ao homem.

\section{Referências}

Andrade, F. A. (2016). Colégio das freiras: educação feminina no curso normal no sul de Goiás (1939/1968). Dissertação: Ensino, Universidade Federal de Goiás - UFG.

Andreotti, A. L. (2006). A administração escolar na Era Vargas e no nacional-desenvolvimentismo (1930-1964). Revista HISTEDBR On-line, 102-123.

Araújo, J. C. S., Freitas, A. G. B. \& Lopes, A. P. C. (2017). As escolas normais no Brasil do Império à República. Alínea.

Azevedo, C. B. \& Stamatto, M. I. S. (2012). Escola da ordem e do progresso: grupos escolares em Sergipe e no Rio Grande do Norte. Liber Livro.

Bardin, L. (2011). Análise de conteúdo. Edições 70, 2011.

Bezerra, A. D. A. (2015). Escola Normal de Ponta Porã, sul de Mato Grosso (1959- 1974). Dissertação: Educação, Universidade Federal de Mato Grosso do Sul - UFMS.

Braga, A. C., \& Mazzeu, F. J. C. (2017). O analfabetismo no Brasil: lições da história. Revista on line de Política e Gestão Educacional, 21 (1), $24-46$.

Brasil. (1946). Decreto-Lei n. 8530 - Lei Orgânica do Ensino Normal. Diário Oficial da República.

Brasil. (1961). Lei n. 4.024 - Diretrizes e Bases da Educação Nacional. Diário Oficial da República.

Brasil. (1971). Lei n. 5.692 - Diretrizes e Bases da Educação Nacional. Diário Oficial da União.

Carvalho, L. B. (2014). Implantação e consolidação da escola normal no sul de Mato Grosso: Escola Normal Jango de Castro, Aquidauana (1949-1975). Dissertação: Educação, Universidade Federal de Mato Grosso do Sul - UFMS.

Escolano, A. \& Frago, A. (2001). Currículo, espaço e subjetividade - a arquitetura como programa. DP\&A.

Gil, A. C. (2017). Como elaborar projeto de pesquisa. (6a ed.). Atlas.

Inácio, C. B. (2017). Estado militar e educação e a formação de professores: as iniciativas da Escola Normal de Uberlândia (1970 - 1980). 2017.167 f. Dissertação (Mestrado em Educação) - Programa de Pós-Graduação em Educação, Universidade Federal de Uberlândia, Uberlândia, 2017.

Ipólito, V. K. \& Almeida, V. F. C. (2020). História Moderna. UniCesumar. 
Research, Society and Development, v. 10, n. 8, e10210816985, 2021

(CC BY 4.0) | ISSN 2525-3409 | DOI: http://dx.doi.org/10.33448/rsd-v10i8.16985

Lemiechek, L. (2014). Aspectos históricos da formação de professores normalistas no município de Laranjeiras do Sul - PR (1946 - 1980). Dissertação: Educação, Universidade Estadual do Oeste do Paraná - UNIOESTE.

Louzada, M. C. S. (2018) Memórias e trajetórias de egressas das Escolas Normais Assis Brasil e São José em Pelotas/RS, no período do governo de Leonel Brizola (1959-1963). Tese: Educação, Universidade Federal de Pelotas - UFPEL.

Marinho, J. Z. S. (2008). Entre letras e bordados: o tecer das tramas na história das normalistas. Dissertação: História, Universidade Federal do Piauí - UFPI.

Martins, A. M. G. S. (2016). A formação de professores primários no Piauí (1947-1961): entre as apropriações e mudanças decorrentes da lei orgânica do ensino normal. Tese: Educação, Universidade Federal do Piauí - UFPI.

Moraes, A. D. J. (2014). História e memória da formação docente em Ituiutaba - MG. Tese: Educação, Universidade Federal de Uberlândia - UFU.

Moura, S. B. (2014). O Colégio São José e a formação das professoras normalistas em Caxias - Maranhão: formando para a igreja, para a pátria e o lar (1949 - 1972). Dissertação: Educação, Universidade Federal do Piauí - UFPI.

Nosella, P., \& Buffa, E. (2002). Schola Mater: a antiga Escola Normal de São Carlos (1911-1933). EdUFSCar.

Nóvoa A. (1995). Os professores e a sua formação. Dom Quixote.

Nunes, C. (2006). A disciplina História da Educação na formação de professores: desafios contemporâneos. Revista História da Educação, 10(19), 173-180.

Ortiz, F. R. (2014). A Escola Normal de moças das elites: um estudo das práticas escolares, culturais e sociais do Colégio Nossa Senhora Auxiliadora (19461961). Dissertação: Educação, Universidade Federal de Mato Grosso do Sul - UFMS.

Ribeiro, P. R. M. (1993). História da educação escolar no Brasil: notas para uma reflexão. Paidéia, (4), 15-30.

Santiago, A. M. S. F. (2015). Vozes e saudades: as narrativas das ex-alunas sobre a Escola Normal Regional Nossa Senhora da Assunção - Guimarães/MA (1957-1961). Dissertação: Educação, Universidade Federal do Maranhão - UFMA.

Saviani, D. (2009). Formação de professores: aspectos históricos e teóricos do problema no contexto brasileiro. Revista Brasileira de Educação, 14(40), 143155.

Saviani, D. (2013). História das Ideias Pedagógicas no Brasil. (4a ed). Campinas: Autores associados.

Simões, C. H. (2014) A formação de professores na Escola Normal Joaquim Murtinho no sul de Mato Grosso no período de 1930 a 1973 . Dissertação: Educação, Universidade Federal de Mato Grosso do Sul - UFMS.

Soares, S. J., \& Fonseca, V. M. (2019). Pesquisa científica: uma abordagem sobre a complementaridade do método qualitativo. Quaestio-Revista de Estudos em Educação, 21(3), 865-881.

Tanuri, L. M. (2000). História da formação de professores. Revista Brasileira de Educação, 14(1), 61-88.

Vasconcelos, M. C. C. (2014). Pesquisa em História da Educação: acervos, arquivos e a utilização de fontes. Fronteiras: Journal of Social, Technological and Environmental Science, 3(3), 33-47. 